\title{
New approaches to the electromagnetic monitoring for improving the regulatory framework "green" building
}

\author{
Marina Grafkina ${ }^{1}$, and Evgeniya Sviridova ${ }^{1 *}$ \\ ${ }^{1}$ Ecological safety of technical systems, Moscow Polytechnic University, Moscow Russia
}

\begin{abstract}
In the regulatory legal base of a "green" construction existing now in the Russian Federation for assessment of an ecological safety of rooms of residential and public buildings criteria of electromagnetic comfort aren't used. Its completion with obligatory assessment of indicators of electromagnetic safety is reasonable. Suggestions for improvement of the existing documents regulating assessment of conformity of real estate objects to ecological requirements are given in article. For the purpose of further development of system of regulation of negative factors of the habitat and electromagnetic safety, authors offer new approach to environmental control of low-frequency electromagnetic fields - transition from measurement of amplitude characteristics to determination of energy parameters. Sanitary and hygienic assessment and regulation of low-frequency electromagnetic fields it is performed separately on intensity of electric and magnetic field that doesn't give an idea of an overall picture of spatial distribution of energy. The energy approach offered by authors will allow to estimate total energy impact of electromagnetic fields per capita, and also to develop new system of regulation of low-frequency electromagnetic fields in energy parameters.
\end{abstract}

\section{Introduction}

Currently, in the Russian Federation with the aim of improving the quality of life of the population, including through the formation of human comfort for the external and internal environment, as well as the safety of life is under development and implementation of "green" technologies in all sectors of the economy, including construction.

The main objective of "green" building is not only a reduction in the consumption of energy and material resources throughout the life cycle of the building, but also to improve the quality of buildings and the comfort of their indoor environment.

For the development of "green" technologies in construction is necessary to improve the regulatory framework and the legislation right. In Russia, developed and used certification

\footnotetext{
corresponding e-mail: evg_sviridova@mail.ru
} 
systems that take into account the requirements of national standards, construction and sanitary norms, rules and guidance documents, as well as the basic provisions of the international LEED rating systems, BREEAM, DGNB and the HQE, including:

- GOST R 54964-2012 "Conformity assessment. Environmental requirements to the objects of real estate ";

- SRT NOSTROY 2.35.4-2011 "Green Building". Residential and public buildings. The rating system for assessing the sustainability of habitat;

- SRT NOSTROY 2.35.68-2012 "Green Building". Residential and public buildings. Taking into account regional peculiarities in the rating system of evaluation of the stability of the environment.

Environmental requirements to properties defined combination of the following basic categories:

- environmental management;

- infrastructure and the quality of the environment;

- the quality of the architecture and layout of the facility;

- comfort and environment of the internal environment;

- the quality of health protection and waste management;

- the rational use of water and stormwater management;

- energy conservation and efficiency;

- protection of the environment during the construction, operation and disposal facility;

- life safety.

In this category of "comfort and internal environment of the environment" includes the following criteria: air-thermal comfort; light comfort; acoustic comfort; protection of the premises from the accumulation of radon; monitoring and control systems engineering support buildings; monitoring and control of air environment.

None of these documents to assess the environmental safety of the habitat is not being used criteria for electromagnetic pollution premises of residential and public buildings, despite the fact that the well-known adverse effects of electromagnetic fields (EMF) on the human body. The list of normative references is present SanPiN 2.2.4.1191-03, which regulates exposure to EMF in a production environment. The application of these sanitary regulations for premises properly, as it does not guarantee favorable conditions habitat for a 24-hour stay of people in residential areas, especially in the light of the main tasks of the "green" construction.

Thus, the need for further improving the regulatory framework for the right "green" construction.

\section{Methodology}

First, we propose to amend the GOST R 54964-2012 on the basis of the existing regulations for electromagnetic safety. In particular, in paragraph 4 "Internal environment Comfort and Ecology" Table 1 "Basic categories and criteria" must add paragraph 4.7 (see. Table 1).

Table 1. Improving Table 1 GOST R 54964-2012 in terms of the criteria of the electromagnetic comfort

\begin{tabular}{|c|l|}
\hline Basic categories & Criterion \\
\hline $\begin{array}{l}\text { 4. Comfort and Ecology of the internal } \\
\text { environment }\end{array}$ & 4.7. Electromagnetic comfort \\
\hline
\end{tabular}


In addition, n. 4 "Comfort and Ecology of the internal environment" Table 2 "Basic category criteria, the minimum environmental requirements and methods of their determination." Table 2 below shows some additional indicators for premi

Table 2. Improving Table 2 GOST R 54964-2012 in the part of the electromagnetic comfort indicator

\begin{tabular}{|c|c|c|c|c|}
\hline Criterion & Indicator & $\begin{array}{l}\text { Minimum } \\
\text { environmental } \\
\text { requirements }\end{array}$ & $\begin{array}{l}\text { Recommended } \\
\text { indicators }\end{array}$ & $\begin{array}{l}\text { Methods for } \\
\text { determining the } \\
\text { minimum } \\
\text { environmental } \\
\text { requirements }\end{array}$ \\
\hline $\begin{array}{l}\text { 4.7.Electr } \\
\text { o- } \\
\text { magnetic } \\
\text { comfort }\end{array}$ & $\begin{array}{l}\text { The electric } \\
\text { field inside the } \\
\text { premises } \\
\text { The magnetic } \\
\text { field inside the } \\
\text { premises } \\
\text { EMF RF } \\
\text { remote control } \\
\text { for the } \\
\text { population in } \\
\text { different } \\
\text { frequency } \\
\text { bands }\end{array}$ & $\begin{array}{l}\text { SanPiN 2971-84 } \\
\text { GN 2.1.8 / 2.2.4. } \\
2262-07 \\
\text { SanPiN 2.2.4 / } \\
\text { 2.1.8.055-96 }\end{array}$ & $\begin{array}{c}0.5 \mathrm{kV} / \mathrm{m} \\
\\
4 \mathrm{~A} / \mathrm{m} \\
\\
\\
25 \mathrm{~V} / \mathrm{m} \\
(30 \mathrm{kHz}- \\
300 \mathrm{kHz}) \\
\\
15 \mathrm{~V} / \mathrm{m} \\
(0.3 \mathrm{MHz}- \\
3 \mathrm{MHz}) \\
\\
10 \mathrm{~V} / \mathrm{m} \\
(3 \mathrm{MHz}- \\
30 \mathrm{MHz}) \\
3 \mathrm{~V} / \mathrm{m} \\
(30 \mathrm{MHz}- \\
300 \mathrm{MHz}) \\
\\
10 \mathrm{~mW} / \mathrm{cm}{ }^{2} \\
(300 \mathrm{MHz}- \\
300 \mathrm{GHz})\end{array}$ & $\begin{array}{l}\text { Evaluation of the } \\
\text { measurements. } \\
\text { The } \\
\text { measurements can } \\
\text { be carried out by } \\
\text { specialized } \\
\text { instrumentation. } \\
\text { Analysis of } \\
\text { project } \\
\text { documentation, } \\
\text { calculations to } \\
\text { reduce them as } \\
\text { part of the project; } \\
\text { measurements }\end{array}$ \\
\hline
\end{tabular}

One of stages of process of the organization of a construction directed to increase in an ecological safety of construction objects is carrying out engineering-ecological researches. Environmental monitoring is a basis for objective assessment of state of environment and an integral part of implementation of basic provisions of engineering-ecological researches.

Well-known negative impact of low-frequency electromagnetic fields on the person, environment, the built-up territories. The main sources of low-frequency electromagnetic fields in the urban environment are: power lines, power transformer substations, distribution points of system of power supply, air electric networks, transport stream, networks of power supply of the land electric transport, etc.

According to the SP 11-102-97 engineering-ecological researches for a construction which part the research of electromagnetic fields is are carried out for assessment of the current state and the forecast of possible changes of the surrounding environment under the 
influence of anthropogenous loading for the purpose of prevention, minimization or liquidation of harmful and undesirable ecological and related social, economic and other consequences and preserving optimum living conditions of the population. In the period of a construction, to operation and liquidation of construction objects environmental monitoring provides control of dynamics of an ecological situation (a condition of natural and technical systems, efficiency of protective and nature protection measures, etc.).

The research of energy pollution shall be performed first of all in case of development of town-planning documentation and designing of housing construction in the mastered territories. At the same time the main sources of harmful effects, its intensity shall be fixed and discomfort zones with excess of admissible level of harmful physical impact are revealed.

Development of new approaches to carrying out and assessment of results of environmental monitoring acquires special relevance at detection of real and potential health hazard of the population of pollution of the habitat. The complex indicator of anthropogenous loading which consists of the most significant factors of negative impact has to be the criterion of quality of the environment defining the state of health of the population.

In previously published papers [2-3], the authors demonstrated the possibility of environmental monitoring of energy parameters of the low frequency of anthropogenic impact, confirming the advisability of further improving the existing legal framework for Electromagnetic Safety and environmental requirements to the objects of "green" construction.

In accordance with the existing methods of evaluation and environmental monitoring of low frequency electromagnetic fields of their level of determination includes the study of amplitude spectrum of the electric and magnetic fields. The research practice is also not customary to define the energy parameters of low-frequency electromagnetic fields, because it is believed that the electromagnetic wave radiation source in the near zone has not yet been formed, so in a study of low-frequency electromagnetic fields EMF energy parameters are not evaluated. Rationing Energy indicators currently holds only for EMF radio frequency spectrum (in this case, the normalized energy exposure and the energy flux density).

However, there are certain techniques [3] to determine the noise energy source parameters in the near zone. Given the similarity of wave processes occurring in the sound and electromagnetic field, the authors propose a new approach to assessing the level of lowfrequency electromagnetic fields - the transition from the measurement of the amplitude characteristics to the definition of energy parameters.

In the near-field zone of EMF, two processes that are qualitatively different in energetic terms take place. The first process is the process of periodic energy exchange between the energy source and the near-field zone (the reactive intensity $I i$ ). Energy is either taken from the source and accumulated in the near-field zone electromagnetic field or is directed back to the source. [4]

The second process is the process of energy radiation (the active intensity $I_{a}$ ). It describes the wave process in the near-field zone. The radiated energy has a rather small value in comparison with the energy periodically accumulated in the electromagnetic field of the near-field zone and then directed to the power supply.

As well as in the general theory of wave processes, there is a concept of the integrated intensity in the electromagnetic field theory, which includes the active and reactive components:

$$
\vec{I}_{k}=\vec{I}_{a}+\vec{I}_{i}
$$


where $\vec{I}_{a}$ is the vector of the active intensity of EMF, $\frac{W}{m^{2}}$;

$\vec{I}_{i}$ is the vector of the reactive intensity of EMF, $\frac{W}{m^{2}}$.

Determination of the EMF energy performance (integrated intensity) will allow gaining a new strong effect of monitoring - electromagnetic energy spatial directional distribution.

\section{Results}

Integrated intensity can be determined by means of the cross spectrum function, which spectrum is computed by multiplication of one spectrum by the complex conjugation of the second spectrum.

The cross spectrum is a complex value. The cross spectrum amplitude characterizes the total energy of EMF in the given point, and the phase is a difference of phases between the intensity of the electrical field and the intensity of the magnetic field.

Thus, the integrated intensity of EMF is equal to:

$$
\begin{aligned}
& I_{k}=E \cdot H^{*}=\left(|E| \cdot \cos \varphi_{1}+i|E| \cdot \sin \varphi_{1}\right) \cdot\left(|H| \cdot \cos \varphi_{2}-i|H| \cdot \sin \varphi_{2}=\right. \\
& =|E| \cdot|H| \cdot\left(\cos \left(\varphi_{1}-\varphi_{2}\right)+i \cdot|E| \cdot|H| \cdot \sin \left(\varphi_{1}-\varphi_{2}\right),\right.
\end{aligned}
$$

where $\mathrm{E}$ is the electric field intensity, $\mathrm{V} / \mathrm{m}$;

$\mathrm{H}$ is the magnetic field intensity, $\mathrm{A} / \mathrm{m}$;

$\mathrm{H}^{*}$ is the complex conjugate value of the magnetic field intensity, $\mathrm{A} / \mathrm{m}$.

At time averaging (for a period), the reactive intensity is converted to zero, and there remains only the active intensity, which can be measured.

For determination of the reactive intensity, $90^{\circ}$ is added to the initial phase of the electric field intensity and its value is gained at the spectrum analyzer's output:

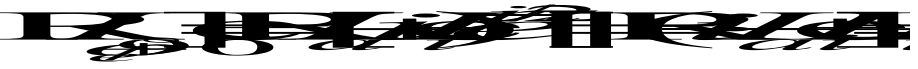

where $I_{a}$ is the active intensity of EMF, $\frac{W}{m^{2}}$;

$I_{i}$ is the reactive intensity of EMF, $\frac{W}{m^{2}}$;

$\varphi_{E}$ is the electric field intensity initial phase, grad.

Thus, in any point of the low frequency EMF, it is possible to find the integrated intensity - the energy parameter of EMF.

For the experimental determination of the energy of low-frequency EMF authors parameters measuring system was developed, which consisted of antenna measurement, oktafon, analog-to-digital converter (ADC) and dual-channel spectrum analyzer.

When measured simultaneously measured the electric and magnetic fields, then converted by the ADC signal is transmitted to the spectrum analyzer and the intensity of the active was determined (the angle between the antennas was 90 degrees).

The experiment was obtained spectrum intensity active in the low-frequency EMI radiation source near zone in absolute units. Active intensity is positive and it has a direction from the radiation source. The maximum value at a frequency of $50 \mathrm{~Hz}$ up to 8.7 $\mathrm{kW} / \mathrm{m}^{2}$. 


\section{Conclusion}

Most have to deal with multiple sources of low-frequency EMF, while not all sources are obvious. Active intensity in this case points to a radiation source, introducing a maximum contribution to electromagnetic pollution at a given point and thus, will develop the most effective methods of protection.

The proposed new authors new approach will provide a comprehensive assessment of comfort objects "green construction" for several indicators of energy (noise, EMF, thermal radiation, vibration) and allow to solve essentially new problems of improve in ecological safety of the built-up territories

\section{References}

1. M.V. Grafkina, B.N. Nyunin, E.Y. Sviridova, Bulletin MGSU, 4, 116 (2014)

2. M.V. Grafkina, B.N. Nyunin, E.Y. Sviridova, Ecology of the urbanized territories, 3, 66 (2014)

3. Bryul and Kjer, Intensity of a sound (Denmark, 2000)

4. L.A. Bessonov, Theoretical bases of electrical equipment: electromagnetic field (The higher school, Moscow, 1998) 